\title{
Effects of Pressure on Tantalum in Contact with Zinc, Indium and Tin*
}

\author{
Yasuo Fujinaga and Tasaku Sato \\ Institute for Materials Research, Tohoku University, Sendai 980-8577, Japan
}

\begin{abstract}
Tantalum and a low melting metal ( $\mathrm{Zn}, \mathrm{In}, \mathrm{Sn})$ are brought in contact under a high pressure of $7 \mathrm{GPa}$ and annealed above the melting temperature of the latter. After quenching and releasing the pressure the lattice constant is measured by means of an X-ray diffraction method. The lattice constant of tantalum is expanded by formation of a terminal solid solution phase. The lattice expansion after heating for 50 min is $0.79,0.50$ and $0.38 \%$ for zinc, indium and tin, respectively. On the other hand, the lattice constant of the low melting metals keeps approximately constant within the present conditions of pressure, temperatures and heating time up to 50 min. Zinc, indium and tin do not form a terminal solid solution phase with tantalum during the heat treatment at $7 \mathrm{GPa}$. They are chemically inactive with tantalum under high pressure and temperature.
\end{abstract}

(Received September 14, 1999; In Final Form November 25, 1999)

Keywords: tantalum, zinc, indium, tin, lattice constant, solid solution, high pressure

\section{Introduction}

A number of studies have been made on the determination of the phase relation of binary alloy systems under high pressure. The measurement of electrical resistance is one of the most useful method for investigation on the phase relation of them. Usually it was carried out by measuring an electrical voltage under a constant current. In some experiments, a foil of an alloy has been used as a sample and electrodes for the measurement. ${ }^{1,2)}$ A typical example is schematically illustrated in Fig. 1(a). The arrangement is a simple scheme and easy handling for setting the sample. Therefore, this method has been applied for measurement of the change in the electrical resistance due to a phase transformation in an alloy. This method has, however, a demerit of having gradient of pressure and temperature along the longitudinal direction of the foil itself. In addition, when the foil shown in Fig. 1(a) cannot be prepared for such as a brittle alloy, the method is also impossible to apply the measurement of the electrical resistance. In order to avoid these disadvantages it is favorable to prepare the separated electrodes to connect the sample in a region of high pressure and temperature as shown in Fig. 1(b). In this case, however, a material of electrodes must be chemically inactive with the sample during the measurement of electrical resistance. At normal pressure tantalum is chemically inactive against some low melting metals in a wide range of temperature. Tantalum is an easy handling material for preparing the electrodes because of its good plasticity. These useful properties of tantalum are required to be kept even under high pressure and temperature.

Phase relations of binary alloys with low melting temperature have been investigated under high pressure. The equilibrium phase diagrams of the binary systems having a terminal element of zinc, indium and tin showed interesting pressure effects such as changes in the eutectic temperature and solubility limit of a primary solid solution as well as appearance of a new intermediate phase. ${ }^{1-6)}$ In the present study, tanta-

${ }^{*}$ A part of this paper was originally published in Japanese in the technical reports of Institute for Materials Research.
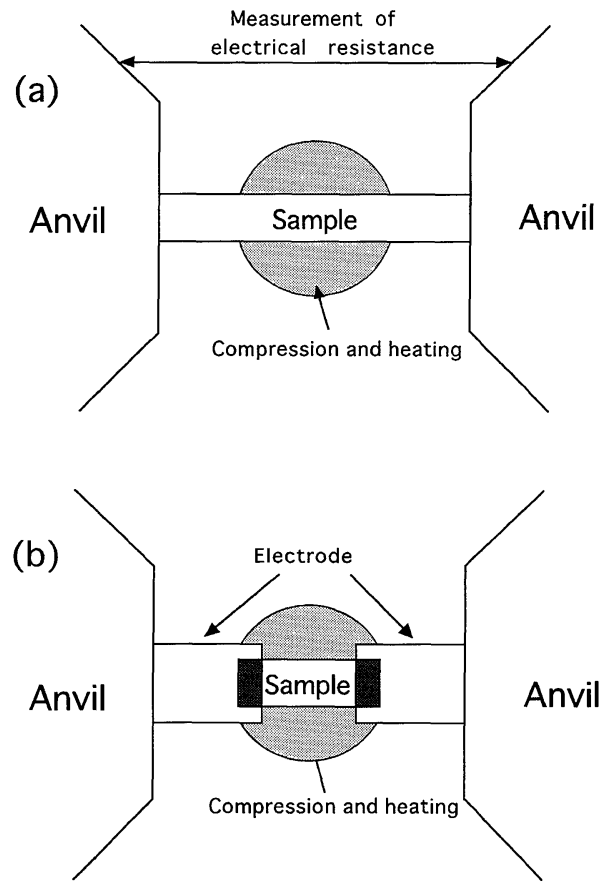

Fig. 1 Schematic illustrations of measurement of electrical resistance under high pressures. (a) A method for using the sample itself as the electrode, (b) a sample in contact with electrodes of another metal.

lum was contacted with the various metals shown above and kept under high pressure and temperature. After quenching and releasing the pressure the crystal structure of the alloys was determined by means of an X-ray diffraction method and the chemical stability of tantalum against zinc, indium and tin was investigated.

\section{Experimental Procedure}

\subsection{Cell assembly}

Foils and powder of tantalum, zinc, indium and tin were prepared from material on the market except powder of indium. The indium powder was made from cutting a foil with 
Table 1 Size, thickness and purity of prepared metals.

\begin{tabular}{ccccc}
\hline Material & $\begin{array}{c}\text { Powder } \\
\text { size }\end{array}$ & Purity (\%) & $\begin{array}{c}\text { Foil } \\
\text { thickness (mm) }\end{array}$ & Purity (\%) \\
\hline Ta & 200 mesh & 99 & 0.01 & 99.95 \\
Zn & $100-200$ mesh & 99.999 & 0.05 & 99.99 \\
In & $\sim 500 \mu \mathrm{m}$ & 99.9 & 0.1 & 99.9 \\
Sn & $150 \mu \mathrm{m}$ & 99.999 & 0.05 & 99.9 \\
\hline
\end{tabular}

a thickness of $0.1 \mathrm{~mm}$. The thickness of the foils, size of the powder and purity of the metals are shown in Table 1. Impurity was not detected in the X-ray diffraction patterns of the prepared pure metals.

Schematic illustrations of the sample assembly are shown in Fig. 2. The foils of tantalum and another metal were cut to a form of a strip and overlapped between discs, $2 \mathrm{~mm}$ in diameter, made from boron nitride with the hexagonal structure. The contacting part of the foils was $0.4-1.0 \mathrm{~mm}^{2}$. The fine powders of tantalum and another metal about $5 \mathrm{mg}$ in total were mixed and inserted in a hole, $1 \mathrm{~mm}$ in diameter and about $0.6 \mathrm{~mm}$ in depth, of a disc made from boron nitride. A pair of the foil- and power-type samples was placed around the center of a cube, edge length $8 \mathrm{~mm}$, made from annealed pyrophyllite.

A cubic-type multianvil press (TRY250) ${ }^{7)}$ was employed for applying a high pressure. The cube of pyrophyllite was pressed by six tungsten carbide anvils, each of which had a rectangular face with edge length $6 \mathrm{~mm}$. The pressures in the experiments were determined in terms of applied load from a previous calibration of the apparatus. The phase changes of bismuth at 2.55 and $7.7 \mathrm{GPa}$ were used for the calibration. The pressure-temperature phase diagram of tin was also used for the calibration purpose. ${ }^{8)}$ The temperature at the sample was measured by means of a $13 \% \mathrm{Rh} / \mathrm{Pt}-\mathrm{Pt}$ thermocouple without correction for the influence of pressure. The temperature of the heat treatment was kept about $50^{\circ} \mathrm{C}$ above the melting temperatures of the low melting metals. A pressuretemperature relation of each metal shown by Cannon ${ }^{9)}$ was applied for giving the temperature of the heat treatment under high pressure. The melting state of the metal was confirmed (a)

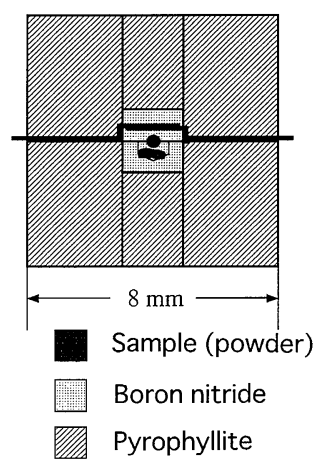

(b)

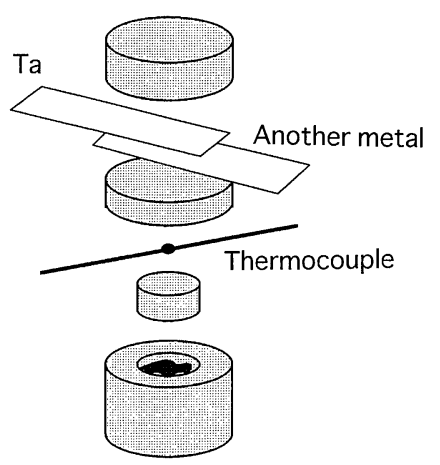

Fig. 2 Sample assembly used for the present study. (a) A vertical section through the center of a cubic cell, (b) an illustration around the foil-type and powder-type samples. by a prominent kink in an electrical resistance and temperature (R-T) curve of the sample in the form of a thin strip.

\subsection{X-ray diffraction examination}

The powder- and foil-type samples were held at selected temperature and heating time at $7 \mathrm{GPa}$, and then they were cooled to ambient temperature within a few seconds and the pressure was released slowly. The boron nitride mixed in the sample during the compression was removed as much as possible, and then each sample was mounted on the DebyeScherrer X-ray diffraction camera and photographed in a film. Since the sample was extremely small, a high power X-ray source with a rotary target of copper was used at $40 \mathrm{kV}$ and $140 \mathrm{~mA}$ for $3-4 \mathrm{~h}$. In order to cut off the $K \beta$ radiation a nickel filter with a thickness of $20 \mu \mathrm{m}$ was used. The lattice constants calculated from the diffraction pattern of metals were carried out by the Nelson-Riley correction using prominent diffraction lines at a high diffraction angle.

\section{Results and Discussion}

\subsection{Lattice constants of zinc, indium and tin}

Figure 3(a) shows the lattice constants of zinc in contact with tantalum $(\mathrm{Zn} / \mathrm{Ta})$ kept at $7 \mathrm{GPa}$ and $720^{\circ} \mathrm{C}$ as a function of heating time. The solid and open symbols correspond to the powder- and foil-type samples, respectively. The broken lines are the values of lattice constants of pure zinc with hcp structure ( $a=0.2665 \mathrm{~nm}, c=0.4947 \mathrm{~nm})$. The lattice constants of $\mathrm{Zn} / \mathrm{Ta}$ are independent of the heating time up to $50 \mathrm{~min}$. This suggests that zinc is chemically inactive against tantalum at $7 \mathrm{GPa}$ and above the melting temperature.

Figure 3(b) shows the lattice constants of indium in contact with tantalum (In/Ta) kept at $7 \mathrm{GPa}$ and $480^{\circ} \mathrm{C}$ as a function of heating time. The structure of indium is tetragonal and the lattice constants are $a=0.32517 \mathrm{~nm}$ and $c=0.49459 \mathrm{~nm}$, drawn with broken lines in the figures. The lattice constants of In/Ta keep the initial values of pure indium. Indium is also chemically inactive against tantalum within the reaction of the given conditions.

The structure of tin is tetragonal ( $\beta$ phase) with the lattice constants of $a=0.5831 \mathrm{~nm}$ and $c=0.3182 \mathrm{~nm}$ at atmospheric conditions. The $\beta$ phase is transformed to a $\gamma$ phase with the bct structure at $9.4 \mathrm{GPa}$ and room temperature. The $\gamma$ phase, however, appears at a low pressure of $3.3 \mathrm{GPa}$ at $305^{\circ} \mathrm{C}$ as the triple point and it is stable between $155-495^{\circ} \mathrm{C}$ at $7 \mathrm{GPa} .{ }^{9)}$ The initial $\beta$-Sn phase in contact with tantalum $(\mathrm{Sn} / \mathrm{Ta})$ was kept at $7 \mathrm{GPa}$ and $570^{\circ} \mathrm{C}$ for the heating time between 2-50 min. Figure 3(c) shows the lattice constants as a function of heating time. We did not also observe a detectable change in the lattice constants of the $\beta$-Sn phase due to the effect of high pressure and temperature. The time independence of the values of the lattice constant means the negligibly small solubility of tantalum in the $\beta$-Sn phase.

A melt of tin in contact with tantalum should initially transform to $\gamma$-Sn at $7 \mathrm{GPa}$ during the solidification process. It was difficult to confirm the solubility of tantalum in the $\gamma$ Sn phase by the present X-ray diffraction method. Measurements of electrical resistance of the foil-type sample were carried out at $7 \mathrm{GPa}$ with different cooling and heating rates (20- 
(a)

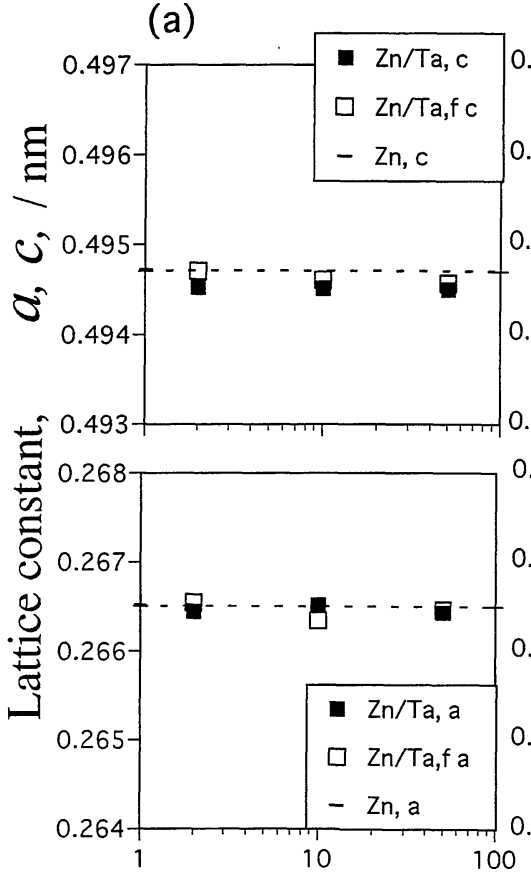

(b)
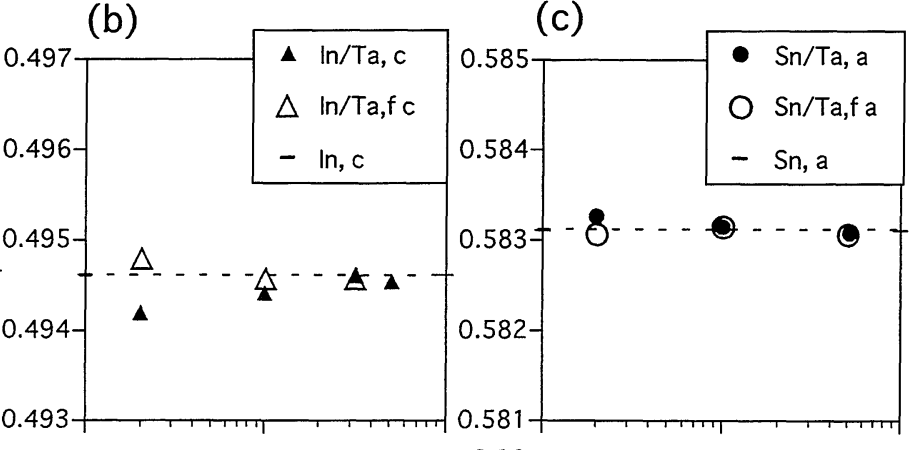
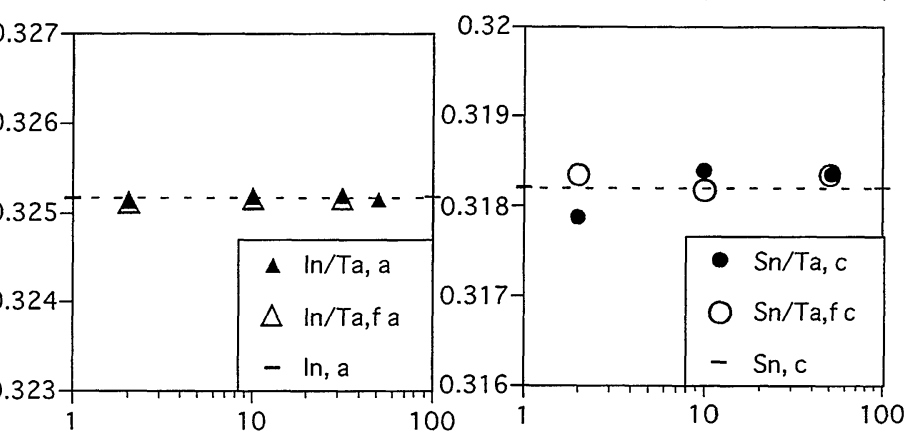

Time, $t / \mathrm{min}$

Fig. 3 Lattice constants of low melting metals versus heating time at $7 \mathrm{GPa}$. Solid symbols: powder-type sample (a,c); open symbols: foil-type sample (fa, fc). (a) $\mathrm{Zn}$ in contact with $\mathrm{Ta}$ at $720^{\circ} \mathrm{C}$, (b) $\mathrm{In} / \mathrm{Ta}$ at $480^{\circ} \mathrm{C}$, (c) $\mathrm{Sn} / \mathrm{Ta}$ at $570^{\circ} \mathrm{C}$.

$300^{\circ} \mathrm{C} / \mathrm{min}$ ). In the R-T curves the transition temperatures corresponding to the liquid $\rightarrow \gamma$ and $\gamma \rightarrow \beta$ phase transformations were approximately invariable with the treatments. The result suggests that the solubility of tantalum in the $\gamma-\mathrm{Sn}$ phase is also not notable in the Sn-Ta system, i.e., the $\gamma-\mathrm{Sn}$ phase keeps the chemical inactivity against the solubility of tantalum at the pressure.

The melting temperatures measured by the R-T curves of $\mathrm{Sn} / \mathrm{Ta}$ was approximately in agreement with that of pure tin at $7 \mathrm{GPa}$. Similar result was obtained in the R-T curves of $\mathrm{In} / \mathrm{Ta}$ and indium. In the case of $\mathrm{Zn} / \mathrm{Ta}$, a kink corresponding to the eutectic (eutectoid) reaction was lowered about $100^{\circ} \mathrm{C}$ from that of the melting temperature of pure zinc. These results suggest that the eutectic (eutectoid) composition of the alloys locates at extremely $\mathrm{Sn}-\mathrm{In}$ - and $\mathrm{Zn}$-rich sides ( $<5 \mathrm{~mol} \%)$ in the binary phase diagrams at $7 \mathrm{GPa}$. This means the chemical stability of tantalum against the low melting metals above the eutectic (eutectoid) temperatures.

As shown in Fig. 3 the notable difference of the lattice parameters is not observed between the powder- and foil-type samples of $\mathrm{Zn} / \mathrm{Ta}$, In/Ta and $\mathrm{Sn} / \mathrm{Ta}$ combinations.

\subsection{Lattice constant of tantalum}

Figure 4 shows the effects of high pressure and temperature on the lattice constant of tantalum reacted with zinc, indium and tin $(\mathrm{Ta} / \mathrm{Zn}, \mathrm{Ta} / \mathrm{In}, \mathrm{Ta} / \mathrm{Sn})$ at $7 \mathrm{GPa}$. The solid and open symbols correspond to powder- and foil-type samples, respectively. The broken line indicates the value of lattice constant of pure tantalum with bcc structure ( $a=0.33058 \mathrm{~nm}$ ).

The lattice constants of $\mathrm{Ta} / \mathrm{Zn}, \mathrm{Ta} / \mathrm{In}$ and $\mathrm{Ta} / \mathrm{Sn}$ increase with increasing the heating time. The effect is especially notable in the case of $\mathrm{Ta} / \mathrm{Zn}$. After heating for $50 \mathrm{~min}$ the lattice expansion of tantalum is $0.79 \%, 0.50 \%$ and $0.38 \%$ for zinc,

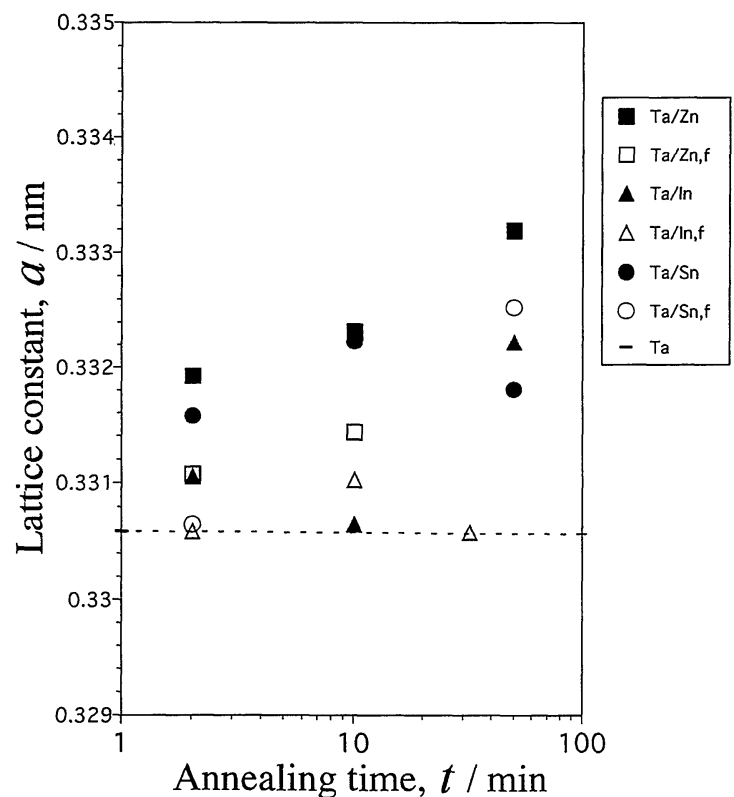

Fig. 4 Lattice constants of tantalum versus heating time above the melting temperatures of $\mathrm{Zn}$, In and $\mathrm{Sn}$ at $7 \mathrm{GPa}$. Solid symbols: powder-type sample in contact with low melting metals; open symbols: foil-type sample in contact with low melting metals.

indium and tin, respectively. Figure 5 shows a series of X-ray diffraction patterns in the case of tantalum reacted with zinc at $7 \mathrm{GPa}$ and $720^{\circ} \mathrm{C}$. The diffraction patterns of pure tantalum and zinc are added for comparison. The diffraction lines of them are indexed in terms of bcc and hcp unit cells as denoted in the figure. Comparing the diffraction lines between $\mathrm{Ta} / \mathrm{Zn}$ and $\mathrm{Zn} / \mathrm{Ta}$, we can observe the notable shift of the diffraction lines of $\mathrm{Ta} / \mathrm{Zn}$ to the low diffraction angle with increasing the 
(a) (b) (c) (d) (e)

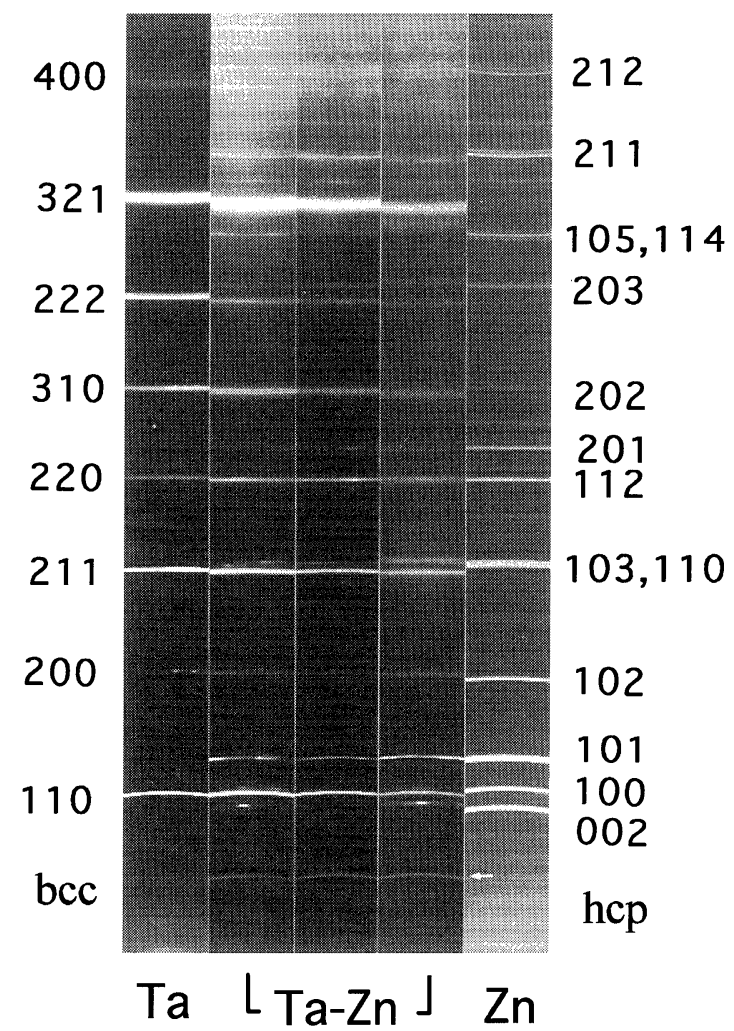

Fig. 5 X-ray diffraction photographs of tantalum reacted with zinc. They were taken after treatments of $7 \mathrm{GPa}$ and $720^{\circ} \mathrm{C}$ in various heating times. Photographs of pure tantalum and zinc are added for comparison. Diffraction lines shown with an arrow at the lowest angle in the $\mathrm{Ta}-\mathrm{Zn}$ alloys are due to boron nitride of the pressure transmitting material. (a) Pure tantalum, (b) heating time of $2 \mathrm{~min}$, (c) $10 \mathrm{~min}$, (d) $50 \mathrm{~min}$, (e) pure zinc.

heating time.

The lattice expansion of tantalum in Fig. 4 seems to be unsaturated at the heating time of $50 \mathrm{~min}$. In order to proceed the reaction between tantalum and zinc at $7 \mathrm{GPa}$ a powder-type sample of $\mathrm{Ta} / \mathrm{Zn}$ was heated at $820^{\circ} \mathrm{C}$ for $50 \mathrm{~min}$ at $7 \mathrm{GPa}$. The lattice constant measured at atmospheric condition was $0.33415 \mathrm{~nm}$, which corresponds lattice expansion of $1.08 \%$. When a curve of the lattice constant versus heating time of $\mathrm{Ta} / \mathrm{Zn}$ given from Fig. 4 is extrapolated to long time, the value $(0.33415 \mathrm{~nm})$ of the lattice constant corresponds about $1000 \mathrm{~min}$ of the annealing time at high pressure. This suggests that the solute content of zinc in tantalum would be saturated within several hours of annealing time at $720^{\circ} \mathrm{C}$.

The lattice constants of the powder-type samples of $\mathrm{Ta} / \mathrm{Zn}$ tend to be larger than those of the foil-type samples. The powder-type samples were kept in the sufficient contact between the metals. On the other hand, the foil-type samples were contacted only at a plane overlapped tantalum and another metal each other. The low values of the lattice constant of the latter may be caused by the insufficient diffusion of solute atoms in tantalum, especially in the case of the heating time of $2 \mathrm{~min}$. On the foil-type sample of tantalum, when it was heated for a long time, the preparation of the sample for the measurement of X-ray diffraction became difficult because of the deterioration of the sample during the treatment.

\subsection{Solid solubility in tantalum}

The equilibrium phase diagram of the Ta-In system at normal pressure shows that the terminal elements are completely immiscible each other in both the liquid and solid states. ${ }^{10}$ ) The $\mathrm{Ta}-\mathrm{Zn}$ and $\mathrm{Ta}-\mathrm{Sn}$ systems also have not been known the terminal solid solutions. The appearance of terminal solid solutions in the tantalum-rich side is a notable pressure effect in the phase diagrams of the Ta-Zn, Ta-In and Ta-Sn binary systems.

The solid solubility of terminal phases of the binary systems depends on the difference between atomic radii of the elements forming the alloy. ${ }^{11)}$ This consideration suggests that the decrease of the size difference between the participating elements is favorable for extent of solubility in primary solid solution. Atomic radii of tantalum, zinc, indium and tin at normal pressure are $0.1457,0.1379,0.1660$ and $0.1620 \mathrm{~nm}$, respectively, for assuming the coordination number $12 .^{12)}$ The compressibility at normal pressure is $\sigma_{\mathrm{Ta}}=$ $0.50 \times 10^{-11} \mathrm{~m}^{2} / \mathrm{N}, \sigma_{\mathrm{Zn}}=1.67 \times 10^{-11} \mathrm{~m}^{2} / \mathrm{N}, \sigma_{\mathrm{In}}=2.43 \times$ $10^{-11} \mathrm{~m}^{2} / \mathrm{N}$ and $\sigma_{\mathrm{Sn}}=0.901 \times 10^{-11} \mathrm{~m}^{2} / \mathrm{N}$. ${ }^{13)}$ When we compare the values of atomic radius and compressibility among the elements, the ratio of atomic radii between tantalum and indium tends to be close each other with increasing the pressure. The similar tendency can be observed between tantalum and tin. In the view point of size difference between the atoms, indium and tin are favorable for increasing the solid solubility in tantalum. It is consistent with the experimental results. On the other hand, since the compressibility of zinc is larger than that of tantalum, the relative atomic size between tantalum and zinc should be enlarged under the pressure. This is unfavorable for the formation of the terminal solid solution in tantalum-rich side with respect to the size effect. It is inconsistent with the experimental result. The effects of zinc with respect to the solubility and lattice expansion of $\mathrm{Ta} / \mathrm{Zn}$ should be interpreted by the other mechanism.

Usually the lattice constant of a primary solid solution depends on the relative atomic size and solute content in solvent. The lattice expansion of tantalum is, therefore, expected to be caused by the solution of another metal with large atomic size. When we applied the Vegard's law for determination of the solute content in the primary solid solution, the solubility in tantalum was estimated to be $3.6 \mathrm{~mol} \%$ for indium and $3.4 \mathrm{~mol} \%$ for tin.

\subsection{Intermediate phases in the binary systems}

An intermediate phase of $\mathrm{InTa}_{3}$ with $\mathrm{Au}-\mathrm{Cu}\left(\mathrm{Ll}_{0}\right)$ type ordered structure ${ }^{14)}$ has been shown in a phase diagram of the Ta-In system. ${ }^{15)}$ Although no phase diagrams are available for the Ta-Sn and Ta-Zn systems, intermediate phases of $\mathrm{Sn}_{3} \mathrm{Ta}_{2}{ }^{16)}$ and $\mathrm{SnTa}_{3}{ }^{16-18)}$ for the former and $\mathrm{Ta}_{6} \mathrm{Zn}_{7}$ and $\mathrm{TaZn}_{2}{ }^{16)}$ for the latter have been reported in these binary systems. All of the intermediate phases were not detected within the present conditions of experiment. At normal pressure the intermediate phases have been detected after sufficient time of heating (about several tens hours) or high temperatures. ${ }^{18)}$ Therefore, we cannot compare the stability of them between the normal and compression states. It can be concluded that the formation of the intermediate phases is not notable within the present conditions of pressure, temperatures and heating 
time.

\subsection{Stability against chemical reaction between tanta- lum and other metals ( $\mathrm{Zn}, \mathrm{In}, \mathrm{Sn})$ under high pres- sure and temperature}

In the present study, tantalum was prepared for a material of electrode under high pressure and temperature. After application of pressure and temperatures the tantalum and low melting metals were kept the initial crystal structures. The lattice constants of $\mathrm{Zn} / \mathrm{Ta}$, In/Ta and $\mathrm{Sn} / \mathrm{Ta}$ were also not influenced by the treatments. We did not also detect the appearance of any kind of intermediate phases as the pressure effect. These results show that tantalum is the favorable material for the present purpose of electrode against the low melting metals. On the other hand, the solubility of the metals in tantalum occurs in $\mathrm{Ta} / \mathrm{Zn}, \mathrm{Ta} / \mathrm{In}$ and $\mathrm{Ta} / \mathrm{Sn}$ combinations at $7 \mathrm{GPa}$ and high temperatures. This means that the electrode of tantalum contributes to the additional electrical resistance during the measurement of R-T curves of zinc, indium and tin alloys. Although we need to pay attention on the effect of solubility of tantalum during the measurement, tantalum can be applied for the electrodes of the measurement of electrical resistance of the alloys within the conditions up to $7 \mathrm{GPa}$ and above the melting temperatures of them.

\section{Acknowledgements}

The authors express their thanks to Professor Y. Syono for his support and encouragement of this study.

\section{REFERENCES}

1) Y. Fujinaga and Y. Syono: High Pressure Research, 15 (1997), 233243.

2) Y. Fujinaga and T. Sato: J. Alloys and Compounds, 209 (1994), 311317.

3) V. K. Fedotov, V. P. Zhebelev, E. G. Ponyatovskii and D. F. Litvin: Sov. Phys. Solid State, 16 (1975), 2156-2160.

4) V. F. Degtyareva, S. A. Ivakhnenko, E. G. Ponyatovskii and V. I. Rashchupkin: Sov. Phys. Solid State, 23 (1981), 951-954.

5) D. E. Gordon and B. C. Deaton: Phys. Rev. B, 6 (1972), 2982-2984.

6) Y. Fujinaga and Y. Syono: Mater. Trans., JIM, 38 (1997), 1063-1066.

7) J. Osugi, K. Shimizu, K. Inoue and K. Yasunami: Rev. Phys. Chem. Jpn., 34 (1964), 1-6.

8) Y. Fujinaga: Jpn. J. Appl. Phys., 32 (1993), L148-L150.

9) J. F. Cannon: J. Phys. Chem. Ref. Data, 3 (1974), 781-824.

10) H. Okamoto: Bulletin of Alloy Phase Diagram, 9 (1988), 56-58.

11) C. S. Barrett and T. B. Massalski: Structure of Metals, 3rd ed., McGrawHill Book Company, New York, (1966), pp. 343-345.

12) L. Pauling: J. Am. Chem. Soc., 69 (1947), 542-553.

13) K. Gschneidner, Jr.: Solid State Phys., 16 (1964), 300-303.

14) A. Raman and K. Schubert: Z. Metallkd., 56 (1965), 44-52 [in Germany].

15) T. B. Massalski: Binary Alloy Phase Diagramss, 2nd ed., ASM International, Material Park Ohio 44073, (1990), pp. 3401, 3441.

16) P. Villars and L. D. Calvert: Pearson's Handbook of Crysallographic Data for Intermetallic Phases, 2nd ed., (The Material Information Society, Materials Park, OH 44073), 5286, 5307.

17) B. T. Matthias, T. H. Geballe, S. Geller and E. Corenzwit: Phys. Rev., 95 (1954), 1435.

18) T. F. Smith: J. Low Temp. Phys., 6 (1972), 171-195. 